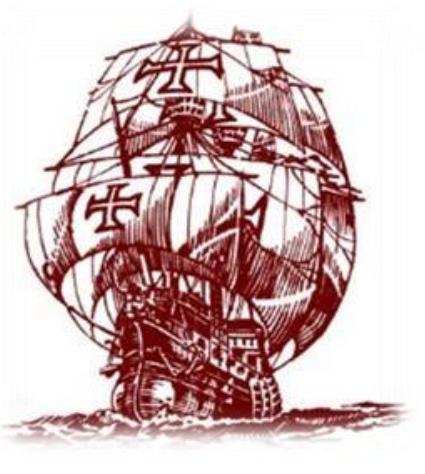

Nau Literária: crítica e teoria de literaturas

www.seer.ufrgs.br/nauliteraria

ISSN 1981-4526 - PPG-LET-UFRGS - Porto Alegre

Vol. 11 N. 01 - 2015

100 anos da geração Orpheu

\title{
Ricardo Reis por outros olhos: a personagem refigurada em $O$ ano de José Saramago
}

\author{
Sara Grünhagen ${ }^{1}$
}

\begin{abstract}
Resumo: Este artigo propõe uma análise do romance $\mathrm{O}$ ano da morte de Ricardo Reis, que se apropria de um heterônimo clássico de Pessoa para problematizar sua visão de alheamento diante do espetáculo do mundo. Enfatizamos o trabalho de refiguração do heterônimo transformado em personagem e inserido num período bastante conturbado da história, procurando ressaltar o caráter questionador e metaficcional dessa obra.

Palavras-chaves: Literatura; Filosofia; Crônica; António Lobo Antunes.

Abstract: This paper proposes an analysis of the romance The year of the death of Ricardo Reis, which uses a classic heteronym by Pessoa in order to discuss his vision of alienation at the spectacle of the world. We focus on the re-figuration of the heteronym transformed in character and set in a very troubled period of history, seeking to emphasize the questioning and metafictional nature of this book.
\end{abstract}

Keywords: Portuguese Literature; metafiction; character.

\section{Introdução}

Se me disserem que é absurdo fallar assim de quem nunca existiu, respondo que também não tenho provas de que Lisboa tenha alguma vez existido, ou eu que escrevo, ou qualquer cousa onde quer que seja (PESSOA In: SARAMAGO, 2011, epígrafe, p. 7).

O ano da morte de Ricardo Reis, publicado em 1984, vem, desde o seu surgimento, causando grande impacto no âmbito da Literatura Portuguesa e até da literatura mundial, graças principalmente a maior projeção da obra de Saramago resultante do prêmio Nobel de Literatura concedido em 1998. A isso se seguiram análises e estudos que ultrapassam as fronteiras dos países de Língua Portuguesa, a exemplo de uma antologia organizada por Harold Bloom dedicada a Saramago - tornada possível em função da tradução das obras do autor - e que contempla também $O$ ano, ao qual o famoso crítico literário se refere com grande admiração

\footnotetext{
${ }^{1}$ Mestranda em literature portuguesa (UERJ) e bolsista CNPq.
} 
(BLOOM, 2005, p. xii). Entretanto, não foi só de críticas positivas que se construiu a fama de $O$ ano; em Portugal, particularmente, a reação à obra foi também negativa, pois o autor estava tratando com o recém-mitificado Fernando Pessoa. Saramago vai na contramão dessa mistificação ao se apropriar do heterônimo Ricardo Reis e refigurá-lo no seu romance, colocando-o diante de uma realidade outra e problematizando o que já se tornava cânone.

Há que se ressaltar que essa opção estética em que se procede a uma certa dessacralização do mito é própria da literatura pós-moderna, que vê na narrativa "um campo propício à problematização e mesmo à deslegitimação de narrativas fundadoras ou identitárias" (REIS, 2006, p. 296). Semelhantemente, a forte intertextualidade presente em $O$ ano - a exemplo de Borges, Camões e, naturalmente, Fernando Pessoa -, a tendência paródica e provocatória, o questionamento da suposta verdade por meio de construções metadiscursivas e metaficcionais e a reescrita ficcional da história são outras características percebidas em Saramago, tanto nesse romance como em outros, a exemplo de Memorial do convento, publicado dois anos antes e concebido mais ou menos na mesma época.

Assim, em Saramago destaca-se essa constante recriação e refiguração - do mito, da história, da dita realidade -, que tem que ver com uma perspectiva pós-moderna de questionamento da relação tanto entre a história e a realidade quanto entre a realidade e a linguagem (HUTCHEON, 1991, p. 34). E no caso de $O$ ano, a relativização que disso resulta se dá não só na problematização da história - Saramago faz Ricardo Reis retornar num momento particularmente conturbado da história portuguesa e europeia -, mas também da própria personagem. Apropriando-se de um dos heterônimos mais conservadores de Pessoa, o que o autor faz é confrontá-lo com o mundo e consigo mesmo e, através de um elaborado trabalho de linguagem que joga com a poética do heterônimo, questionar sua postura passiva de mero observador, reescrevendo e reinscrevendo, assim, essa personagem enquanto figura da ficção. Para Rebelo:

Aqui é que reside precisamente a grandeza do desafio. Situar Ricardo Reis na quotidianeidade, dar-lhe uma existência civil e inseri-lo no plano da história, bulir com ele e mexer-lhe com os nervos, é uma opção ironicamente perversa que põe à prova o mito e a integridade da legenda (REBELO, 1985, p. 145)

É, portanto, nisso que chamamos de refiguração de Ricardo Reis que o presente estudo pretende focar, enfatizando o trabalho de linguagem do autor ao recuperar o heterônimo, seu pensamento e também seu caráter múltiplo para criar uma nova narrativa em que a personagem assume um papel central, como ponto de partida e de chegada de um romance profundamente questionador. Para tanto, será feita uma breve introdução do heterônimo Ricardo Reis conforme 
pensado por Fernando Pessoa, seguida da análise propriamente do modo indireto com que é retratado no romance, já como personagem refigurado. Por fim, ainda pensando a personagem Ricardo Reis, procuraremos indicar outros aspectos importantes do livro de Saramago, enfatizando-se o contexto histórico no qual o romance é situado, que serve como pano de fundo para a história mas também funciona como uma constante provocação à postura imperturbável que Ricardo Reis quer para si e que, em $O$ ano, por vezes falha em alcançar diante de um mundo prementemente em chamas.

\section{0 heterônimo Ricardo Reis}

Não sei, bem entendido, se realmente não existiram, ou se sou eu que não existo. Nestas coisas, como em todas, não devemos ser dogmáticos (PESSOA, 1974, p. 95).

Ricardo Reis, nascido em 1887 na cidade do Porto, é um médico monárquico que, até ser trazido de volta a Portugal por Saramago, vivia no Brasil, tendo se expatriado voluntariamente em 1919 por não concordar com o regime republicano instaurado no país. Trata-se de um dos heterônimos mais conhecidos de Pessoa, e parte dessa sua fama também se deve à recriação a que procede Saramago em $O$ ano da morte de Ricardo Reis. Antes, porém, de analisar como se dá essa recriação ou refiguração do heterônimo, cabe indicar brevemente como ele é concebido por Pessoa.

Na sua famosa carta a Adolfo Casais Monteiro de 13 de janeiro de 1935, ano de sua morte, Pessoa discorre sobre a gênese de sua heteronímia, apresentando também uma certa biografia de Ricardo Reis, Álvaro de Campos e do mestre Alberto Caeiro. No caso do primeiro, Pessoa diz, por exemplo: "pus em Ricardo Reis toda a minha disciplina mental, vestida da música que lhe é própria” (PESSOA, 1974, p. 94). Reis é a faceta, a subpersonalidade ou a figura (todos termos constantes da referida carta) mais disciplinada e rigorosa de Fernando Pessoa: "Reis [domina o português] melhor do que eu, mas com um purismo que considero exagerado" (PESSOA, 1974, p. 98). Para além dos dados biográficos já citados - nascimento, profissão e expatriação política -, Pessoa também dá detalhes sobre a constituição física e a formação do poeta das odes: "Ricardo Reis é um pouco, mas muito pouco, mais baixo, mais forte, mais seco [que Alberto Caeiro] [...] Cara rapada todos [...] Reis de um vago moreno mate [...] Ricardo Reis, educado num colégio de jesuítas [...] é um latinista por educação alheia, e um 
semi-helenista por educação própria” (PESSOA, 1974, p. 97-98). Nessa mesma carta, Pessoa diz ainda que, dos três heterônimos, Ricardo Reis foi um dos primeiros a surgir:

Aí por 1912, salvo erro (que nunca pode ser grande), veio-me à ideia escrever uns poemas de índole pagã. Esbocei umas coisas em verso irregular (não no estilo Álvaro de Campos, mas num estilo de meia regularidade), e abandonei o caso. Esboçara-se-me, contudo, numa penumbra mal urdida, um vago retrato da pessoa que estava a fazer aquilo. (Tinha nascido, sem que eu soubesse, o Ricardo Reis) (PESSOA, 1974, p. 96).

Mais tarde, tendo já se manifestado o mestre Alberto Caeiro, Pessoa tratou de "lhe descobrir [...] uns discípulos", e Reis finalmente apareceu por inteiro: “Arranquei do seu falso paganismo o Ricardo Reis latente, descobri-lhe o nome, e ajustei-o a si mesmo, porque nessa altura já o via" (PESSOA, 1974, p. 96.). É interessante notar que, segundo essa gênese descrita por Pessoa, a figura de Ricardo Reis, como a dos outros heterônimos, só surge depois dos seus poemas, assim como o ortônimo Pessoa só surge após o heterônimo, só se afirma como poeta

pela linguagem. Isso porque os poemas de Chuva Oblíqua, de FernandoPessoa, teriam sido escritos após o surgimento do mestre Alberto Caeiro, com $O$ Guardador de Rebanhos: "Foi o regresso de Fernando Pessoa Alberto Caeiro a Fernando Pessoa ele só” (PESSOA, 1974, p. 96).

Tudo isso diz respeito, portanto, à construção de um universo ficcional que se dá por um trabalho de linguagem, e é este universo que Saramago vai recuperar e ficcionalizar, transformando, também pela linguagem, o heterônimo em personagem de ficção romanesca.

\section{Ricardo Reis personagem}

Vivem em nós inúmeros; / Se penso ou sinto, ignoro / Quem é que pensa ou sente. / Sou somente o lugar / Onde se pensa e sente (PESSOA, 2007, p. 109).

Em $O$ ano da morte de Ricardo Reis, o heterônimo de Pessoa não só ressurge em outro contexto como vai apresentando, ao longo do romance, mudanças significativas, motivo pelo qual falamos em refiguração. Esse processo já começa na contracapa da edição portuguesa de $O$ ano, em que temos uma citação da carta de Pessoa sobre a gênese heteronímica seguida de um novo dado do autor do romance, anunciando o ponto a partir do qual a narrativa se inicia:

Ricardo Reis nasceu em 1887 (não me lembro do dia e do mês, mas tenho-os algures), no Porto, é médico e está presentemente no Brasil.

Fernando Pessoa (Carta de 13 de janeiro de 1935)

Ricardo Reis regressou a Portugal depois da morte de Fernando Pessoa. José Saramago 
Essa citação de Pessoa é o que serve, a princípio, para caracterizar a personagem do livro, pois ela não é logo apresentada ou descrita, mas vai se revelando aos poucos, indiretamente. Seu regresso a Portugal é já anunciado na primeira frase do romance, mas de forma sutil e algo poética, numa clara alusão a Camões, ainda que invertida: "Aqui o mar acaba e a terra principia" (SARAMAGO, 2011, p. 9). Seguem-se descrições do tempo, da cidade, do Highland Brigade e seus passageiros, num tom melancólico que parece anunciar não só a chegada mas também o destino da personagem, que em Lisboa irá aportar e, como já antecipa o título do livro, morrer: "a melancolia alastra, faz emudecer os viajantes, não há sombra de alegria neste regresso. A alfândega é uma antecâmara, um limbo de passagem, que será lá fora" (SARAMAGO, 2011, p. 13, grifo nosso). As primeiras descrições do viajante de regresso surgem ainda sem que ele seja anunciado, e já o ato em si de descrevê-lo aparece como problema:

Um homem grisalho, seco de carnes, assina os últimos papéis [...] Acompanha-o um bagageiro cujo aspecto físico não deve ser explicado em pormenor, ou teríamos de prosseguir infinitamente o exame, para que não se instalasse a confusão na cabeça de quem viesse a precisar de distinguir um do outro, se tal se requer, porque deste teríamos de dizer que é seco de carnes, grisalho, e moreno, e de cara rapada, como daquele foi dito já, contudo tão diferentes, passageiro um, bagageiro outro (SARAMAGO, 2011, p. 13-14).

As diferenças entre os dois são, aqui, mais de posição social do que físicas. O viajante grisalho talvez seja parecido com o bagageiro porque tem a mesma origem portuguesa, o que também só se ficará sabendo depois, nas poucas palavras que ele troca com o taxista: "vivi em Lisboa, sou português [...] Há dezasseis anos que não vinha a Portugal" (SARAMAGO, 2011, p. 16). Ainda, o fato de o viajante estar sem barba não fora mencionado antes no livro, mas se refere à mencionada descrição dos heterônimos feita por Fernando Pessoa: "Cara rapada todos" (PESSOA, 1974, p. 97). Esse jogo de referências e alusões que abundam já nas primeiras páginas permeia todo o livro, sendo a base para a refiguração da personagem executada pelo autor. É o que se verifica fortemente nas alusões não explícitas ao que poderíamos chamar de pensamento de Ricardo Reis, expresso em poemas, cartas ou mesmo descrições dos outros heterônimos e de Pessoa, pensamento este que muitas vezes se contradiz com as atitudes do presente: "É o diálogo corrente, conversa sempre igual em casos assim, mas neste de agora há um elemento de falsidade, porquanto o viajante não tem assuntos a tratar em Lisboa, nenhum assunto que tal nome mereça, disse uma mentira, ele que um dia afirmou detestar a inexactidão" (SARAMAGO, 2011, p. 19). Trata-se de uma referência a uma caracterização de Reis feita por Álvaro de Campos e que serve bem para definir a figura do heterônimo sendo recuperada no 
romance: "Falava-se de mentir, e ele disse: 'Abomino a mentira, porque é uma inexactidão'. Todo o Ricardo Reis - passado, presente e futuro - está nisto" (PESSOA, 1980, p. 271).

Outras características conhecidas do heterônimo pessoano também vão surgindo indireta e sutilmente, como suas preferências políticas: "olhou o café de relance, Royal de seu nome, exemplo comercial de saudades monárquicas em tempo de república, ou remanescência do último reinado, aqui disfarçado de inglês ou francês, curioso caso este" (SARAMAGO, 2011, p. 17). Não está dito que ele é monárquico, não ainda, mas sua figura vai sendo construída aos poucos, em conversas e gestos, em deambulações e situações cotidianas: "A Ricardo Reis distraiu-o também da pergunta que a si próprio fizera ter chegado à Praça do Rio de Janeiro, que foi do Príncipe Real e quiçá o torne a ser um dia, quem viver verá" (SARAMAGO, 2011, p. 71, grifo nosso).

A primeira descrição propriamente da personagem também é indireta, e os dados apresentados na contracapa do livro, assim como o nome do heterônimo, só aparecem quando o recém-chegado vai dar entrada no hotel:

Escreve no livro das entradas, a respeito de si mesmo, o que é necessário para que fique a saberse quem diz ser, na quadrícula do riscado e pautado da página, nome Ricardo Reis, idade quarenta e oito anos, natural do Porto, estado civil solteiro, profissão médico, última residência Rio de Janeiro, Brasil, donde procede, viajou pelo Highland Brigade (SARAMAGO, 2011, p. 20).

Esse inventário de informações pessoais - que ecoa a descrição sumária feita por Pessoa - é incômodo para Reis, para quem aquilo "parece o princípio duma confissão, duma autobiografia íntima, tudo o que é oculto se contém nesta linha manuscrita, agora o problema é descobrir o resto, apenas" (SARAMAGO, 2011, p. 20-21). O modo indireto com que Reis vai sendo apresentado funciona justamente no sentido de refletir essa imprecisão dos dados que de concreto pouco ou nada tem; afinal, quem é realmente Ricardo Reis? O projeto do livro vai ser tentar descobrir esse "resto" oculto da identidade do heterônimo realizado no espaço do romance:

Se somente isto sou [...] quem estará pensando agora o que eu penso, ou penso que estou pensando no lugar que sou de pensar, quem estará sentindo o que sinto, ou sinto que estou sentindo no lugar que sou de sentir, quem se serve de mim para sentir e pensar, e, de quantos inúmeros que em mim vivem, eu sou qual, quem, Quain, que pensamentos e sensações serão o que não partilho por só me pertencerem, quem sou eu que outros não sejam ou tenham sido ou venham a ser (SARAMAGO, 2011, p. 24).

Para além da intertextualidade anunciada com a ode de Reis ("Vivem em nós inúmeros", PESSOA, 2007, p. 109), o trecho brinca com o nome do autor borgiano do livro que Reis traz do Highland Brigade: The god of the labyrinth, de Herbert Quain. Não por acaso também uma ficção da qual Saramago se apropria e materializa no livro (SARAMAGO, 1999), o livro de 
Herbert Quain acompanha Ricardo Reis ao longo de toda a sua trajetória em Lisboa, mas acaba desaparecendo novamente quando, no final, Reis decide levá-lo consigo ao partir com Pessoa, deixando assim "o mundo aliviado de um enigma" (SARAMAGO, 2011, p. 465).

O trocadilho quem/Quain e as reiteradas reflexões ontológicas de Reis apontam para o seu caráter plural; o heterônimo personificado está em busca de respostas após a morte do seu criador mas é confrontado com o labirinto da ficção da identidade: “Talvez que eu tenha voltado a Portugal para saber quem sou, Tolice, meu caro, criancice, alumbramentos assim só em romances místicos e estradas que vão a Damasco, nunca se esqueça de que estamos em Lisboa, daqui não partem estradas" (SARAMAGO, 2011, p. 129). A resposta quem dá é Pessoa, figurado no romance num movimento oposto, mas complementar, ao de Reis:

Se de um lado Ricardo Reis, personagem falsamente verdadeiro, que era só um nome, uma voz e uma biografia, adquire um corpo, convive com os homens, realiza-se de certa forma, por outro o personagem real - Fernando Pessoa - que perdera com a morte o seu contorno humano, adquire forma literária, transforma-se em ser fictício, sombra, imagem ora visível ora invisível, a quem o discurso dá vida (CERDEIRA DA SILVA, 1989, p. 104).

Os encontros entre criador e criatura que ocorrem ao longo do livro são bastante ricos e ajudam na construção principalmente dessa figura de Reis, explorando o caráter multifacetado dos dois: "Então como tem passado, um deles fez a pergunta, ou ambos, não importa averiguar, considerando a insignificância da frase" (SARAMAGO, 2011, p. 86). De fato, nos diálogos entre eles parece não importar quem fala, não tanto ou nem sempre pela insignificância das frases mas mais pela identidade conjunta dos dois:

Quem estiver a olhar para nós, a quem é que vê, a si ou a mim, Vê-o a si, ou melhor, vê um vulto que não é você nem eu, Uma soma de nós ambos dividida por dois, Não, diria antes que o produto da multiplicação de um pelo outro, Existe essa aritmética, Dois, sejam eles quem forem, não se somam, multiplicam-se (SARAMAGO, 2011, p. 101).

Aqui, a ausência de verbos dicendi para indicar os interlocutores, marca importante da prosa de Saramago, também serve para reforçar essa pluralidade de identidades: não será um problema se, na leitura, houver confusão quanto a quem está falando, já que os dois são o mesmo multiplicado. Trata-se da despersonalização de Pessoa sendo romanceada numa clara intersecção entre plano discursivo e plano narrativo: a multiplicidade de Ricardo Reis e Fernando Pessoa aparece não só como tema recorrente na história como se revela pela própria linguagem.

Além disso, no romance Fernando Pessoa também funciona como uma voz crítica de Reis, apontando incoerências e contradições e, também pela via indireta, ajudando a caracterizar um personagem que, querendo saber quem é, vai se diferenciando cada vez mais 
do heterônimo. Assim, o poeta idílico do "Vem sentar-te comigo, Lídia, à beira do rio" (PESSOA, 2007, p. 30) aparece tendo um caso com uma nova e providencial Lídia, não mais musa, mas criada de hotel, e Pessoa é quem comenta, em diferentes momentos:

\begin{abstract}
Meu caro Reis, você, um esteta, íntimo de todas as deusas do Olimpo, a abrir os lençóis da sua cama a uma criada de hotel, a uma serviçal, eu que me habituei a ouvi-lo falar a toda a hora, com admirável constância, das suas Lídias, Neeras e Cloes, e agora sai-me cativo duma criada, que grande decepção (SARAMAGO, 2011, p. 128).
\end{abstract}

Bravo, vejo que você se cansou de idealidades femininas incorpóreas, trocou a Lídia etérea por uma Lídia de encher as mãos, que eu bem a vi lá no hotel, e agora está aqui à espera doutra dama (SARAMAGO, 2011, p. 199).

O que eu não esperava era que você fosse tão persistente amante, para o volúvel homem que poetou a três musas, Neera, Cloe e Lídia, ter-se fixado carnalmente em uma, é obra (SARAMAGO, 2011, p. 304).

Tais contradições, recorrentes no texto, vão aparecer também na relação que o personagem vai estabelecendo (ou tentando não estabelecer) com o turbulento contex to político em que se insere, como se verá mais adiante. O heterônimo Reis, sendo inúmeros, revela-se uma personagem bastante complexa, múltipla e inconstante, e todas essas questões analisadas funcionam no sentido de caracterizá-lo no romance, ainda que de modo indireto - por prenúncios, diálogos, situações cotidianas, registros poéticos e mesmo contradições. O próprio modo de figuração mostra-se importante para marcar a complexidade e a multiplicidade de Reis, num texto atravessado por digressões e divagações, poemas, referências e personagens externos, contrastes e confrontos. O labirinto, assim, não é só o do livro que acompanha Reis, mas é o do próprio texto, o da identidade de Reis, o da literatura e da poesia revisitadas e transformadas.

\title{
4 O espetáculo do mundo de $O$ ano da morte de Ricardo Reis
}

Ouvi contar que outrora, quando a Pérsia / Tinha não sei qual guerra, / Quando a invasão ardia na Cidade / E as mulheres gritavam, / Dois jogadores de xadrez jogavam / O seu jogo contínuo (PESSOA, 2007, p. $51)$.

$O$ ano da morte de Ricardo Reis parte de um dado biográfico deixado em aberto na descrição da gênese heteronímica pessoana: Ricardo Reis não morreu, como é o caso de Alberto Caeiro, por exemplo (PESSOA, 1974, p. 97). O título do livro já anuncia, subversivamente, o desfecho do livro, e no texto datilografado (assim como na primeira edição) ele vem seguido do subtítulo "romance", abandonado posteriormente (SARAMAGO, 1983). Os títulos, em 
Saramago, requerem uma atenção especial, na medida em que podem servir para questionar ou problematizar o próprio gênero com que se está trabalhando:

O título funciona, em José Saramago, como afirmação de paradigma discursivo, ou até, nalguns casos, como explícita regência de género. Os romances de Saramago surgem, então, como manual, como memorial, como história, como anuário de incidência biografista, como evangelho ou como ensaio. Esta dominância do título como alusão paradigmática não significa, contudo, uma sujeição passiva a géneros pré-estabelecidos; ela pode trazer consigo (e é isso que normalmente ocorre) a revisão ou mesmo a subversão dos géneros e dos campos institucionais: a enunciação de um novo evangelho (que é também um anti-evangelho), a reformulação da história oficial ou a reconstituição de (parte de) uma biografia (REIS, 1998, p. 14, grifo no original).

Assim, nessa parcial reconstituição biográfica que é $O$ ano, Saramago dá continuidade ao gesto criador de Pessoa e, agora pela prosa, também procura "arrancar" Reis do seu "falso paganismo". Inserindo Ricardo Reis num novo espaço e tempo, a Lisboa do conturbado ano de 1936, o autor procura confrontá-lo com sua visão de que "Sábio é o que se contenta com o espetáculo do mundo" (PESSOA, 2007, p. 36). A questão que parece se colocar no livro é: diante de um espetáculo realmente dramático, é possível mesmo apenas assistir, não se implicar? O poema "Ouvi contar que outrora, quando a Pérsia” é emblemático dessa postura alheada que Reis almeja: dois jogadores de xadrez cercados pelo drama da guerra, mas inabaláveis no seu jogo:

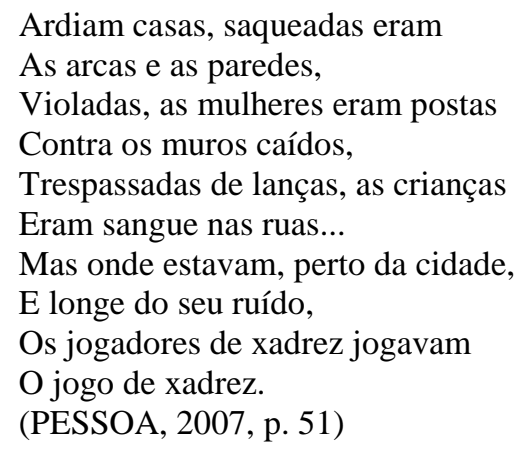

Em $O$ ano, Ricardo Reis de fato é figurado como um jogador tentando limitar-se a jogar seu xadrez: “esta é a página, não outra, este o xadrez, e nós os jogadores, eu Ricardo Reis, tu leitor meu [...] mudado em jogador, e de xadrez [...] por nossa parte imitemos os persas desta história" (SARAMAGO, 2011, p. 336). Entretanto, o ano de 1936 compreende um período histórico que oferece um espetáculo particularmente dramático, que figura de forma expressiva no livro: o avanço do fascismo na Itália e a guerra contra a Etiópia, com a constituição do chamado império italiano (SARAMAGO, 2011, p. 172-73, 292, 333); a intensificação do poder de Hitler na Alemanha (SARAMAGO, 2011, p. 288), o descumprimento do pacto de Locarno e a invasão à Renânia (SARAMAGO, 2011, p. 223), além de fortes campanhas de propaganda 
nazista, das quais Portugal também é alvo (SARAMAGO, 2011, p. 239, 406); as revoltas e as greves em França (SARAMAGO, 2011, p. 332, 391); as eleições na Espanha ganhas pela esquerda e logo seguidas de golpe militar (SARAMAGO, 2011, p. 170, 290, 415-6), com um desfecho trágico de mais de dois mil mortos (SARAMAGO, 2011, p. 439-440); e, no contexto português, o fortalecimento do Estado Novo e de Salazar (SARAMAGO, 2011, p. 91-93), com obras e ações populistas (SARAMAGO, 2011, p. 122, 172) e forte movimento de nacionalismo (SARAMAGO, 2011, p. 289, 333), a criação da Mocidade Portuguesa (SARAMAGO, 2011, p. 406), num espelho da Juventude Hitleriana e com forte adesão por parte da população (SARAMAGO, 2011, p. 422), os comícios contra o comunismo e a criação da Legião Portuguesa (SARAMAGO, 2011, p. 449), além da revolta frustrada dos marinheiros, que culmina no desfecho do livro (SARAMAGO, 2011, p. 459).

Todos esses eventos vão sendo revelados quase sempre de forma indireta e desordenada - como no caso da própria figuração da personagem -, seja pelos jornais que Ricardo Reis lê, seja por situações vividas e conversas tidas com pessoas de seu convívio. E a cada novo episódio, próximo ou distante, o poeta tenta manter-se afastado, quer apenas ler o jornal, não porque "fosse leitor assíduo", mas porque, "por falar do mundo geral, servia de barreira contra este outro mundo próximo e sitiante, podiam as notícias daquele de além ser lidas como remotas e inconsequentes mensagens" (SARAMAGO, 2011, p. 55). Mas esse alheamento vai se mostrando cada vez mais difícil, e mesmo os acontecimentos distantes se interpõem, reclamam uma atenção do jogador concentrado em seu próprio jogo:

Addis-Abeba está em chamas, ardiam casas, saqueadas eram as arcas e as paredes, violadas as mulheres eram postas contra os muros caídos, trespassadas de lanças as crianças eram sangue nas ruas. Uma sombra passa na fronte alheada e imprecisa de Ricardo Reis, que é isto, donde veio a intromissão, o jornal apenas me informa que Addis-Abeba está em chamas [...] em AddisAbeba não consta que estivessem jogadores de xadrez jogando o jogo do xadrez (SARAMAGO, 2011, p. 334-335).

Nesse jogo de intertextualidade entre o que Reis lê no jornal sobre a guerra da Etiópia e seu poema sobre os jogadores de xadrez, fica marcada a refiguração da personagem no livro; aqui, como em outros trechos, vão surgindo as contradições entre o Reis heterônimo e o Reis personagem, entre a postura que Reis ambiciona e o modo com que a personagem se realiza no livro, implicando-se, ainda que a contragosto, nos acontecimentos que a atropelam. $\mathrm{O}$ auge desse seu envolvimento inevitável surge nas cenas finais do livro, quando Reis presencia, horrorizado, o bombardeio aos marinheiros, entre os quais se encontra Daniel, irmão de Lídia:

Entra em casa, atira-se para cima da cama desfeita, escondeu os olhos com o antebraço para poder chorar à vontade, lágrimas absurdas, que esta revolta não foi sua, sábio é o que se contenta 
com o espectáculo do mundo, hei-de dizê-lo mil vezes, que importa àquele a quem já nada importa que um perca e outro vença (SARAMAGO, 2011, p. 461).

Reis não sabe o que fazer, comove-se com a situação, sente o drama "como se tivesse sido ele o que quis ir ao mar e acabou apanhado na rede" (SARAMAGO, 2011, p. 461). Esse ser "apanhado na rede" reflete todo o movimento do livro, que vai enredando Ricardo Reis numa trama que é ao mesmo tempo sutil e opressiva, encurralando-o no seu próprio jogo. Tanto que, no final, a única saída para Reis parece ser a morte:

"E a si mesmo pergunta se é ele, este, o que os escreveu, porque lendo não se reconhece no que está escrito, foi outro esse desprendido, calmo e resignado homem, por isso mesmo quase deus, porque os deuses é assim que são, resignados, calmos, desprendidos, assistindo mortos (SARAMAGO, 2011, p. 247).

Talvez, justamente para que Reis pudesse continuar sendo quem é, sua morte seja anunciada já no título do livro e consumada ao final da trama na qual o heterônimo é inserido; afinal, só na morte entrevê-se a possibilidade de limitar-se a assistir, e ainda assim essa postura é questionada por Pessoa:

Só estando morto assistimos, e nem disso sequer podemos estar certos [...] e contudo eu não me sinto como se apenas assistisse, ou, se realmente assisto, não sei o que em mim assiste, todos os meus actos, todas as minhas palavras, continuam vivos, avançam para além da esquina a que me encosto (SARAMAGO, 2011, p. 159-160).

Reis decide acompanhar seu criador, só sobrevivendo a ele durante os nove meses em que Pessoa poderia continuar na Terra como lembrança. Morto, o Ricardo Reis personagem talvez possa agora apenas assistir ao espetáculo do mundo, que dali por diante "não promete soberbas felicidades" (SARAMAGO, 2011, p. 289). No entanto, como sugere o Pessoa do romance, resta-lhe ainda uma espécie de sobrevida: seus poemas também permanecem vivos, avançam por conta própria, assim como sua figura, tornada personagem de ficção, recuperada e problematizada, acaba por ganhar vida (e morte), sobrevivendo pela literatura.

\section{Considerações finais}

Aqui, onde o mar se acabou e a terra espera (SARAMAGO, 2011, p. 465).

A apropriação de outros textos é, como se viu, marca de uma escrita pós-moderna que recorre à intertextualidade com vistas a repensar a história, a literatura e a noção de verdade, marca esta que se manifesta ainda em várias outras obras de Saramago. Trata-se de um tipo 
específico de apropriação, que por vezes se volta para o passado para recontar a história dos que ficaram à margem, dos que também não "foram nada", segundo a frase da propaganda nazista que surge no livro:

Como escreveram os estudantes alemães, Nós não somos nada, aquilo mesmo que murmuraram, uns para os outros, os escravos que construíram as pirâmides, Nós não somos nada, os pedreiros e os boieiros de Mafra [...] porventura nascerá para nós o dia em que todos seremos alguma coisa, quem isto agora disse não se sabe, é um pressentimento (SARAMAGO, 2011, p. 419).

A autointertextualidade - alusão ao já publicado Memorial do convento - assim como a intervenção do narrador a anunciar um futuro possível, ainda que distante, assinalam esse estilo do autor, que se apropria para reinventar, revelar uma outra face, mas também criticar. Essa crítica não raro é feita como uma forma de oposição a outro tipo de apropriação, a exemplo da que é feita pelo Estado Novo quando se vale da figura de Camões, "cantor sublime das virtudes da raça" (SARAMAGO, 2011, p. 392), para fins de panfletagem do regime. Para Rebelo, é esta “compreensão dolorosa e lúcida da história” que leva Saramago a "“carnavalizar' textos de outros autores, a projectar-se ironicamente na narrativa com alusões directas a outras obras suas, numa tentativa deliberada de desfazer a ilusão do literário" (REBELO, 1985, p. 147).

Assim, quer com Camões - com quem se fecha o ciclo do livro, estando a terra agora diante de uma longa espera até o fim daquele período -, quer com Pessoa, quer com Borges e outros, é nesse processo de apropriação que $O$ ano da morte de Ricardo Reis se constrói, refigurando um heterônimo clássico tanto para questionar um alheamento controverso diante do espetáculo dramático do mundo quanto para realizá-lo no espaço do romance. Com isso, a poética de Ricardo Reis é problematizada assim como Fernando Pessoa é desmistificado, mas também se presta uma homenagem à sua poesia, na medida em que o romance assegura uma sobrevida à personagem-heterônimo e dramatiza o próprio ato poético, fazendo da literatura um instrumento metaficcional de reflexão.

\section{Referências}

BLOOM, Harold (org.). Introduction. In: Bloom's Modern Critical Views: José Saramago. Philadelphia: Chelsea House Publishing, 2005. p. ix-xviii.

CERDEIRA DA SILVA, Teresa Cristina. O ano da morte de Ricardo Reis: entre o fingir e o existir nos labirintos da história. In: José Saramago entre a história e a ficção: uma saga de portugueses. Lisboa: Publicações Dom Quixote, 1989. p. 103-192.

HUTCHEON, Linda. Poética do pós-modernismo: história, teoria, ficção. Trad. Ricardo Cruz. Rio de Janeiro: Imago, 1991. 
PESSOA, Fernando. Carta a Adolfo Casais Monteiro de 13 de janeiro de 1935. In: Obras em prosa. Org. Cleonice Berardinelli. Rio de Janeiro: Aguilar, 1974. p. 93-100.

. Notas para a recordação do meu mestre Caeiro. In: Textos de crítica e de intervenção. Lisboa: Ática, 1980. p. 265-272. . Poesia completa de Ricardo Reis. Org. Manuela Parreira da Silva. São Paulo: Companhia das Letras, 2007.

REBELO, Luís de Sousa. José Saramago: O Ano da Morte de Ricardo Reis. Revista Colóquio/Letras, Lisboa, n. 88, p. 144-148, nov. 1985.

REIS, Carlos. História crítica da Literatura Portuguesa: do neo-realismo ao pós-modernismo. Lisboa: Verbo, 2006. v. 9.

. Introdução: o escritor em construção. In: . Diálogos com José Saramago.

Lisboa: Caminho, 1998. p. 8-20.

SARAMAGO, José. 14 maio 2010. Algumas provas da existência real de Herbert Quain. Disponível em: <http://www.josesaramago.org/algumas-provas-da-existencia-real-de-herbertquain>. Acesso em 5 março 2015. . Memorial do convento. São Paulo: Companhia das Letras, 2013. . O ano da morte de Ricardo Reis. Lisboa: Caminho, 1984. . O ano da morte de Ricardo Reis. São Paulo: Companhia das Letras, 2011. - [s.d.]. $O$ ano da morte de Ricardo Reis: romance. Disponível em:

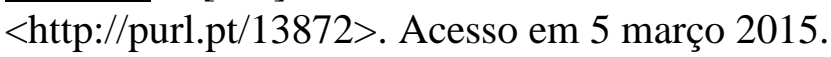

